\title{
Complementary feeding and associated factors: Assessing compliance with recommended guidelines among postpartum mothers in Nigeria
}

\author{
Kolade A. Afolabi ${ }^{1}$, Adebukunola O. Afolabi ${ }^{2}$, Monisola Yetunde J. Omishakin ${ }^{3}$
}

\author{
AFFILIATION \\ 1 Department of Community Health, College of Health Sciences, Obafemi \\ Awolowo University, Ile-Ife, Nigeria \\ 2 Department of Nursing Services, Obafemi Awolowo University Teaching \\ Hospitals Complex, Ile-Ife, Nigeria \\ 3 Department of Nursing Science, Redeemer's University, Ede, Nigeria
}

\section{CORRESPONDENCE TO}

Kolade A. Afolabi. Medical and Health Services, Obafemi Awolowo University, Ile-Ife, Osun State, Nigeria. E-mail: doctorafolabi2@yahoo.com

Popul. Med. 2021;3(June):17
ORCID ID: https://orcid.org/0000-0002-4565-9891

\section{KEYWORDS}

complementary feeding, postpartum mothers, infants, Nigeria

Received: 25 March 2021, Revised: 8 June 2021, Accepted: 14 June 2021

\begin{abstract}
INTRODUCTION Malnutrition in childhood has been linked with inappropriate and ineffective feeding practices especially during the first year of life. This study assessed the knowledge and factors associated with complementary feeding among postpartum mothers in Nigeria.

METHODS A cross-sectional study was performed in Osun State, Nigeria, in September 2019. Sample size was estimated using Fisher's formula for simple proportion and mothers were selected through multi-stage sampling. Data from 193 postpartum mothers were analyzed using SPSS software version 22 at univariate, bivariate and multivariate levels, $\mathrm{p}<0.05$ was considered significant.

RESULTS Findings showed that $28.0 \%$ of postpartum mothers practiced exclusive breastfeeding, 39.9\% introduced complementary feeding within the first 3 months, $32.1 \%$ commenced complementary feeding between the 4 th and 5 th month, $36.3 \%$ of the mothers fed their infants with minimum meal frequency, $52.3 \%$ fed their infants with the minimum
\end{abstract}

dietary diversity, and $25.4 \%$ fed their infants with minimum acceptable diets. Regression analysis revealed that minimum meal frequency was significantly associated with having good knowledge about complementary feeding (OR=2.21; 95\% CI: $1.31-3.73, \mathrm{p}=0.03)$, tertiary education $(\mathrm{OR}=0.18$; 95\% CI: $0.05-0.59, \mathrm{p}=0.01$ ) and household food security (OR=0.49; 95\% CI: 0.26-0.94, p=0.03). Minimum acceptable diet remained significantly associated with mothers having good knowledge about complementary feeding (OR=2.67; 95\% CI: 1.38-5.14, $\mathrm{p}=0.003$ ) and highest educational level (OR=0.11; 95\% CI: 0.02-0.71, $\mathrm{p}=0.02$ ).

CONCLUSIONS Postpartum mother's nutritional knowledge, education level and household food security were main predictors of complementary feeding practices among postpartum mothers, effective nutritional intervention on infants' feeding should therefore take cognizance and address these variables.

\section{INTRODUCTION}

Malnutrition in childhood remains a significant public health concern, especially in developing countries ${ }^{1}$, where poor child feeding practices, high prevalence of common childhood diseases such as diarrhoea, malaria, pneumonia exert a serious negative impact on health outcomes ${ }^{2}$. Consequently, approximately $45 \%$ of mortalities among children aged $<5$ years are related to undernutrition, with approximately $33 \%$ of these deaths resulting from inadequate feeding practices ${ }^{3}$. These nutrition-related morbidities and mortalities mostly occur in low- and middleincome countries, especially in Sub-Saharan Africa and Asia ${ }^{4}$. At the same time, about one-third of these malnutrition cases are attributable to inappropriate nutrition and ineffective feeding practices, which occur during the first year of life ${ }^{5}$ especially from the sixth month of life when only breastmilk cannot sufficiently meet the dietary needs of the infants and for which an appropriate and effective complementary feeding is expected to be introduced.

Furthermore, a global estimate showed that about 22.9\% 
of children aged $<5$ years are stunted while Central Africa accounted for $32.5 \%$, Southern Africa $28.1 \%$, Northern Africa $17.6 \%$ and West Africa accounted for $31.4 \%$. In Nigeria, data from the Nigeria Demographic and Health Survey, NDHS ${ }^{6}$ showed that $37 \%$ of children are stunted, and $19 \%$ are severely stunted. The breakdown of these figure varies across the six geopolitical zones of the country, with the North-West and North-East regions recording the highest prevalence for stunting, wasting and under-weight. In contrast, the SouthEast and South-South recorded lowest prevalence. A higher proportion of children in rural areas were also recorded to be malnourished than those in urban areas ${ }^{6}$.

Similarly, the Nigeria National Nutrition and Health Survey $(\mathrm{NNHS})^{7}$ revealed that acute malnutrition among children aged $<5$ years in Nigeria was between $5 \%$ and $9.9 \%$. In comparison, the prevalence of underweight was about $19.9 \%$ which is close to $22 \%$ obtained in the West and Central Africa regions. The NNHS further revealed that the prevalence of stunting was $32 \%$ and has been considered as the largest burden of malnutrition in Nigeria since 2014, with some states in the North-West and North-East Nigeria recording a significantly high prevalence of $\geq 40 \%$. The above have been observed to be direct and indirect consequences of inappropriate complementary feeding practices.

Complementary feeding involves the introduction of other forms of foods and or liquids from six months of age when breast milk only can no longer meet the dietary requirements of infants ${ }^{6}$. It is the transition from exclusive breastfeeding to family foods beginning from 6 months of age and continuity of breastfeeding up to two years of age. It is the period when malnourishment usually begins in infants thus contributing significantly to the high incidence of malnutrition observed among children aged $<5$ years $^{8}$. The WHO consequently recommended that complementary feeding should be timely, adequate in quantity, have variety, of appropriate frequency and consistency using a variety of foods combination to accommodate the nutritional needs of the growing child while continuing breastfeeding. In contrast, inadequate quantities, qualities and inappropriate combination of complementary foods in addition to ineffective feeding practices have been found to pose a serious nutritional risk to infants' wellbeing ${ }^{9}$, including growth failure, stunting, delayed sexual maturation, impaired cognitive and intellectual development, and impaired immune system ${ }^{10}$.

To ensure effective feeding practices for infants globally, the World Health Organization (WHO) recommended the following core indicators to ensure appropriateness and optimal combination of complementary foods for infants and young children. These indicators include: early initiation of breastfeeding; exclusive breastfeeding up to 6 months of age; continued breastfeeding till the age of two years; introduction of solid, semi-solid or soft foods; ensuring minimum dietary diversity; minimum meal frequency; and minimum acceptable diet. This is in addition to other optional dietary indicators such as intake of iron-fortified or iron-rich foods; continued breastfeeding up till two years; age-related breastfeeding, and milk feeding frequency, especially for non-breastfed children ${ }^{11}$. The WHO further indicated that minimum dietary diversity (MDD), minimum meal frequency (MMF) and minimum acceptable diet (MAD) are more related to adequate complementary feeding.

Despite several nutrition related policies and interventions in Nigeria, such as Baby Friendly Initiatives (BFI) and the Nigeria National Policy on Infant and Young Child Feeding (IYCF), studies on complementary feeding have observed several variations in the pattern, timing, quality and quantity of complementary foods among mothers in different regions in the country. For instance, a study conducted in North-West Nigeria reported that $17.8 \%$ of the infants studied commenced complimentary food between the 1st and 2 nd months while $41.2 \%$ of the infants commenced complementary foods from the $3 \mathrm{rd}$ month ${ }^{12}$. A similar finding was reported in Cross River State, Nigeria, where it was found that $85.4 \%$ of children aged $<5$ years had early introduction of complementary foods ${ }^{13}$.

Early introduction of complementary foods (before the 6th month) has been found to be associated with a varying degree of health risks and childhood illnesses, including food-borne infectious diseases ${ }^{14}$.

The above are in addition to the fact that the proportion of children aged $\geq 6$ months who were fed following IYCF practices in Nigeria remain low ${ }^{15}$. In contrast, the proportion of infants who were fed according to recommended minimum acceptable diet in Nigeria decreased from $30 \%$ in 2008 to $10 \%$ in $2013^{16}$ with only a marginal increase to $11 \%$ in $2018^{6}$. Studies have investigated predisposing factors to ineffective feeding practices in most West African countries; for instance, WHO identified cultural beliefs as barrier to effective feeding practices ${ }^{3}$. This assertion was corroborated by a study in West Africa which identified sociocultural myths and misconceptions about childhood feeding as determinants of infant and young child feeding practices in a review of complementary feeding practices across West African countries ${ }^{14}$. A similar study in Kenya concluded that cultural beliefs and food taboos strongly influenced optimal infant feeding practices in Kenya ${ }^{17}$. The above are in addition to poor knowledge about complementary feeding and basic nutritional needs observed to influence complementary feeding among mothers in Northwestern Nigeria ${ }^{18}$. In addition, the Nigeria Federal Ministry of Health reported that the commonest predisposing factors of malnutrition in the first two years of life in Nigeria are related to inappropriate complementary feeding practices, while in most cases, the diets introduced are inadequate concerning the quantity of food given, nutritional value, energy, protein, micronutrients, quantities and frequency of feeding ${ }^{19}$.

Furthermore, a study on complementary feeding practices among mothers of children under five years in Lagos, Nigeria, reported a significant relationship between timing for introduction of complementary foods and 
nutritional status of infants ${ }^{10}$. There is, however, a dearth of information regarding mothers' compliance with feeding recommendations and guidelines using standard indicators and the influence of maternal characteristics such age, education level, occupation, marital status, socioeconomic status, place of residence and parity in this study area; hence this study aimed at assessing the level of knowledge about complementary feeding among postpartum mothers in Osun State, Nigeria. This study also examined complementary feeding practices among postpartum mothers and identified factors associated with complementary feeding practices among mothers in Osun State. These were to identify enabling factors that can encourage mothers and primary care givers to adopt effective child feeding practices for optimal wellbeing of infants and young children.

\section{METHODS}

\section{Study setting}

This study was conducted in Osun State, South-West Nigeria, between 2 and 30 September 2019. Osun state covers an area spanning approximately $12820 \mathrm{~km}^{2}$. Osun state is divided into three Senatorial districts with 30 Local Government Areas (LGAs) and an area office. The state is located within the interior of the cocoa belt of the South-West Nigeria. According to the 2006 National Population Census, Osun state has an estimated population of about 3.4 million consisting of 1.74 million males and 1.68 million females. Osun state has 30 Local Government Areas (LGAs) and an area office, and is distributed into the three Federal Senatorial districts namely: Osun Central Senatorial district, Osun East Senatorial district and Osun West Senatorial district. Nineteen out of the 30 Local Government Areas (LGAs) are designated as rural Local Government Areas while 11 are considered urban. A rural Local Government Area is a Local Government Area that has one or two small towns as the principal settlements. The major ethnic groups in Osun state are Yorubas while major sub-ethnic groups are Ife, Ijesha, Oyo, Ibolo and Igbomina, although the state also accommodates other ethnic groups from other parts of Nigeria such as the Ibos, Itsekiris, Ijaws, Hausas, Fulanis, Igalas, and several other ethnic groups. Yoruba and English are the official languages. The people of Osun state are mostly farmers, producing cash crops such as cocoa, and palm produce, and food crops such as yam, maize, cassava, beans, plantain, banana, and cocoyam. This is in addition to other skilled professionals having sources of income in the state.

\section{Study design}

The study was a descriptive cross-sectional study conducted in September 2019. The study involved postpartum mothers attending clinics in the selected local government areas.

\section{Study population - sample size determination}

The study included postpartum mothers in selected Local Government Areas in Osun state, Nigeria. The selected Local
Government Areas were Ife Central, Ife East, Oriade and Atakunmosa West Local Government Areas.

Using Fisher's formula for estimating sample size, $\mathrm{n}=\mathrm{Z}^{2} \mathrm{pq} / \mathrm{d}^{2}$, where $\mathrm{n}=$ desired sample size, $\mathrm{Z}=$ standard normal deviation at $95 \%$ confidence level, $\mathrm{z}=1.96, \mathrm{p}=0.11$ (proportion of infants fed with minimum acceptable diet ${ }^{13}$, $\mathrm{q}=1-\mathrm{p}=0.89, \mathrm{~d}=$ degree of accuracy desired, taken to be 0.05 , $95 \%$ level of confidence and degree of accuracy at 0.05 and $15 \%$ attrition rate, minimum sample estimated was however increased to 200 mothers to give wider coverage to the study and to make the sample size more representative. Data from 193 postpartum mothers were, however, analyzed giving a response rate of $96.5 \%$.

\section{Sampling technique}

Postpartum mothers were selected through multistage sampling technique. In stage one, Osun East Senatorial district was selected out of the three Senatorial districts in Osun state by simple random sampling technique (balloting). In the second stage, two rural and two urban Local Government Areas namely Oriade, Ife Central, Ife East and Atakunmosa West Local Government Areas were selected from a list of rural and urban LGAs within the Senatorial district ${ }^{20}$ by simple random sampling technique (balloting) giving a total of four LGAs. In stage three, one Primary Healthcare Center (PHC) was purposively selected (PHCs with highest number of daily attendees obtained during a preliminary survey) from each rural and urban LGAs to give a total of four PHCs. In contrast, in the fourth stage, 50 postpartum mothers who met the inclusion criteria were purposively selected in the Primary Healthcare Centers. Mothers were selected during their visit to the PHCs in selected Local Government Areas. Selection of mothers continued daily until the required number of mothers from each Primary Healthcare Center was attained.

\section{Inclusion Criteria}

Postpartum mothers whose infants were six months old were included in this study. This was to reduce the possibility of recall bias about pregnancy history and feeding type of index child in the first six months of life.

\section{Exclusion Criteria}

Mothers whose infants had gross congenital or chronic abnormalities such as cleft lips, cleft palates or any other gross neurological deficits that could impair anthropometric measurements were excluded from this study.

\section{The instrument for data collection}

Semi-structured questionnaire was used to collect data from mothers. The questionnaire organized into different sections which obtained information about the background characteristics of mothers, child's pregnancy history, history of delivery and immunization, child's age, sex and child's breastfeeding history. This section was adapted 
from Demographic and Health Survey questionnaire ${ }^{6}$. Another section of the questionnaire was adapted from the Food and Agricultural Organization (FAO) guidelines for assessing nutrition-related model questionnaires ${ }^{21}$. This section had 10 items which assessed mother's knowledge about complementary feeding. An additional section of the questionnaire obtained information on the household food security status. This section was adapted from the 6-item food security scale of the United States ${ }^{22}$. The section contains six items for assessing food security status of each household. An additional section of the questionnaire was also adapted from Food and Agriculture Organization (FAO) dietary assessment ${ }^{23}$ which serve as 24 -hour infants' food recall section. The section obtained information on mother's feeding practices based on WHO/IYCF recommended indicators: Minimum meal frequency, Minimum dietary diversity, and Minimum acceptable diet. Information regarding these indicators were obtained by recall of food and liquid consumed by infants in the previous day prior to data collection.

\section{Validity of research instruments}

Face and content validity of the research instruments was ensured by subjecting the instruments to review by experts in the field of Public Health, Paediatrics and Child Health, Nutrition and Dietetics, Demography and Social Statistics. Each item of the instruments was reviewed to ensure appropriateness and ability to meet the stated objective of the study. Necessary corrections were made on the research instruments after review by experts before data collection.

\section{Reliability of research instruments}

Internal consistency of the questionnaire was examined by calculating Cronbach's alpha for the questionnaire and a value of 0.74 was obtained.

\section{Training of research assistants}

Three research assistants were trained on the aim and objectives of the study as well as their role during the data collection, explanation of the questionnaire to infants' mothers and ability to use the Yoruba version of the questionnaire for better understanding of infants' mothers.

\section{Data collection and scoring}

Mother's knowledge about complementary feeding was assessed using 10 items in the questionnaire. Each correct answer was scored 1 while an incorrect answer scored 0 . Scores on the 10-item scale assessing mother's knowledge about complementary feeding were also summed up to give a total of 10; mothers who scored 0-4 were categorized as having poor knowledge about complementary feeding while mothers who scored 5-10 were categorized as having good knowledge. Household food security status was assessed using 6 items adapted from the 6-item food security scale of the USA ${ }^{20}$. Each of the options 'often true, sometimes true' in items 1 and 2 of the scale scored 1 while 'never true' scored of 0 . A 'yes' in items 3, 5 and 6 also scored 1 while 'no' scored 0 . 'Almost every day' and 'some days, but not every day' in item 4 scored 1 while the option 'only 1 or 2 days' scored 0 . These scores were summed up to a maximum of 6 points and a minimum of 0 points. Total score of $0-1$ was categorized as high food security, scores 2-4 were categorized as low food security, while scores 5-6 were categorized as very low food security.

Mother's socioeconomic status was evaluated as a composite variable using mother's education level, employment status and average monthly income. Mothers who had no formal education scored 1 point, primary education 2 points, secondary education 3 points, while mothers who had tertiary education scored 4 points; mothers who were unemployed scored 1 point, while mothers who were employed (self-employed, Government or employed in the private sector) scored 2 points. Mothers who receive less than $30000 \mathrm{NGN}$, the minimum wage in Nigeria at time of this study, scored 1 point while mothers who earned $\geq 30000$ NGN (10000 Nigerian Naira about 24 US\$) scored 2 points. All scores were summed up to a minimum of 3 points and a maximum of 8 points. Mothers who scored a total of 3-4 points were categorized as low socioeconomic status, 5-6 points were categorized as middle socioeconomic status, while 7-8 points were categorized as high socioeconomic status ${ }^{24}$.

\section{Data analysis}

The outcome variable in this study was mother's complementary feeding practices. This was assessed based on indicators recommended by the WHO Guideline on Infants and Young Child Feeding. The indicators are minimum meal frequency, minimum dietary diversity, and minimum acceptable diet.

Minimum Meal Frequency (MMF) is the proportion of infants who received at least the recommended minimum meal frequency appropriate for age in the last 24 hours prior the survey: 2-3 feeding times for infants aged 6-9 months and 3-4 times daily for infants aged 10-12 months in the last 24 hours $^{25-27}$.

Minimum Dietary Diversity (MDD) ${ }^{11}$ is the proportion of children aged $\geq 6$ months who received food from at least four out of the seven recommended food groups in the last 24 hours prior the survey. The seven foods groups used for calculating minimum dietary diversity indicator are: grains, roots and tubers; legumes and nuts; dairy products like milk; fleshy foods such as meat and fish; eggs; fruits and vegetables rich in vitamin A; other fruits and vegetables. The dietary diversity score ranged from $0-7$ with a minimum of 0 if none of the food groups is consumed and 7 if all the food groups are consumed. Thus, from the dietary diversity score, the minimum dietary diversity indicator was estimated using the WHO recommended cut-off point with a value of 1 if the child had eaten at least four out of the seven groups of 
foods (designated as 'adequate' in this study) and 0 if less (designated as 'inadequate').

Minimum acceptable diet in this study was considered as a composite variable involving minimum dietary diversity and minimum meal frequency: infants who received both the minimum diversity and the minimum meal frequency the previous day are considered to have met the WHO recommended minimum acceptable diet ${ }^{11}$.

The independent variables include mother's knowledge about complementary feeding and selected sociodemographic characteristics. These variables have been observed to influence feeding practices of children aged $<5$ years in previous studies ${ }^{25-27}$. These variables include mother's age, parity, education level, employment status, socioeconomic status, and household food security status.

Data entry and analysis was done using IBM SPSS software version 25. Analysis was done at univariate, bivariate and multivariate levels: univariate analysis was done and findings presented using frequency (n) and percentage (\%) distribution tables. Association between complementary feeding practices, mother's knowledge about complementary feeding and selected sociodemographic characteristics of the mother (age, parity, education level, employment status, socioeconomic status, and household food security status) were examined at the bivariate level using chisquared test while the simultaneous effects of independent variables on the outcome variable were examined using logistic regression analysis. A p-value $<0.05$ was considered statistically significant.

\section{RESULTS}

\section{Sociodemographic characteristics of postpartum mothers}

Findings from this study revealed that $39.9 \%$ of the mothers were aged $25-29$ years while $5.2 \%$ were aged $15-19$ years, $6.2 \%$ had no formal education, $59.6 \%$ had secondary school education, $25.4 \%$ had tertiary education, $14.0 \%$ were unemployed, $63.7 \%$ were self-employed while $65.3 \%$ earned below 30000 NGN monthly (Table 1). Seventy-two percent of the mothers received skilled antenatal care during pregnancy of index child, $73.1 \%$ delivered their index child in a hospital or healthcare facility, while $28.0 \%$ practiced exclusive breastfeeding (Table 2).

\section{Complementary feeding practices among postpartum mothers}

Findings also revealed that $71.5 \%$ of the mothers had good knowledge about complementary feeding (Table 3). Results also revealed that $39.9 \%$ of mothers introduced complementary feeding within the first 3 months, $32.1 \%$ commenced complementary feeding between the 4 th and 5th month, $36.3 \%$ fed their infants with minimum meal frequency, $52.3 \%$ fed their infants with the minimum dietary diversity, while $25.4 \%$ fed their infants with minimum acceptable diets (Table 3).
Table 1. Sociodemographic characteristics of mothers in Osun State, Nigeria 2019 ( $\mathrm{N}=193)$

\begin{tabular}{|c|c|c|}
\hline Variables & $\mathrm{n}$ & $\%$ \\
\hline \multicolumn{3}{|l|}{ Age (years) } \\
\hline $15-19$ & 10 & 5.2 \\
\hline $20-24$ & 57 & 29.5 \\
\hline $25-29$ & 77 & 39.9 \\
\hline $30-34$ & 38 & 19.7 \\
\hline $35-39$ & 11 & 5.7 \\
\hline \multicolumn{3}{|l|}{ Marital status } \\
\hline Married & 178 & 92.2 \\
\hline Single & 13 & 6.7 \\
\hline Widowed & 2 & 1.0 \\
\hline \multicolumn{3}{|l|}{ Family type } \\
\hline Monogamous & 147 & 76.2 \\
\hline Polygamous & 33 & 17.1 \\
\hline Single parents & 13 & 6.7 \\
\hline \multicolumn{3}{|l|}{ Place of residence } \\
\hline Rural & 97 & 50.3 \\
\hline Urban & 96 & 49.7 \\
\hline \multicolumn{3}{|l|}{ Ethnicity } \\
\hline Yoruba & 137 & 71.0 \\
\hline Hausa & 30 & 15.6 \\
\hline Igbo & 19 & 9.8 \\
\hline Urhobo/Itsekiri & 7 & 3.6 \\
\hline \multicolumn{3}{|l|}{ Religion } \\
\hline Christianity & 117 & 60.6 \\
\hline Islam & 69 & 35.8 \\
\hline Traditionalist & 7 & 3.6 \\
\hline \multicolumn{3}{|l|}{ Education level } \\
\hline No education & 12 & 6.2 \\
\hline Primary & 17 & 8.8 \\
\hline Secondary & 115 & 59.6 \\
\hline Tertiary & 49 & 25.4 \\
\hline \multicolumn{3}{|l|}{ Employment status } \\
\hline Not employed & 27 & 14.0 \\
\hline Self employed & 123 & 63.7 \\
\hline Government employed & 29 & 15.0 \\
\hline Employed in private sector & 14 & 7.3 \\
\hline \multicolumn{3}{|c|}{ Average monthly income (NGN) } \\
\hline$<30000^{*}$ & 126 & 65.3 \\
\hline$\geq 30000$ & 67 & 34.7 \\
\hline \multicolumn{3}{|l|}{ Socioeconomic status } \\
\hline High & 40 & 20.7 \\
\hline Middle & 119 & 61.7 \\
\hline Low & 34 & 17.6 \\
\hline \multicolumn{3}{|c|}{ Household food security status } \\
\hline High & 77 & 39.9 \\
\hline Low & 46 & 23.8 \\
\hline Very low & 70 & 36.3 \\
\hline
\end{tabular}

* 30000 NGN was the monthly minimum wage payable in Nigeria at the time of this study. NGN: 10000 Nigerian Naira about 24 US\$. 


\section{Factors associated with complementary feeding practices among postpartum mothers}

Bivariate analysis (Table 4) revealed that mother's knowledge about complementary feeding was significantly associated with meal frequency $(\mathrm{p}=0.02)$, meal diversity $(\mathrm{p}=0.01)$ and acceptable diets $(\mathrm{p}=0.01)$. Findings at bivariate level of analysis also showed that mother's employment status was significantly associated with acceptable diet ( $\mathrm{p}=0.001$ ), while mother's monthly income was significantly associated with meal frequency $(\mathrm{p}=0.04)$. Findings at bivariate level of analysis also showed that household food security status was significantly associated with meal

Table 2. Reproductive characteristics of mothers in Osun State, Nigeria 2019 ( $N=193)$

\begin{tabular}{|c|c|c|}
\hline Reproductive variables & n & $\%$ \\
\hline \multicolumn{3}{|l|}{ Parity } \\
\hline Primipara & 41 & 21.2 \\
\hline Multipara & 148 & 76.7 \\
\hline Grand multipara & 4 & 2.1 \\
\hline \multicolumn{3}{|l|}{ Antenatal care during index pregnancy } \\
\hline Received skilled antenatal care & 139 & 72.0 \\
\hline Did not receive skilled antenatal care & 54 & 28.0 \\
\hline \multicolumn{3}{|l|}{ Place of delivery of index child } \\
\hline Hospital/healthcare facility & 141 & 73.1 \\
\hline Mission/traditional birth facility & 30 & 15.5 \\
\hline Home birth & 22 & 11.4 \\
\hline \multicolumn{3}{|l|}{$\begin{array}{l}\text { Time of initiation of breastfeeding of } \\
\text { index child after birth }\end{array}$} \\
\hline Within 1 hour & 35 & 18.1 \\
\hline Between 1 hour and 24 hours & 92 & 47.7 \\
\hline After 24 hours & 66 & 34.2 \\
\hline \multicolumn{3}{|l|}{ Pattern of feeding of index child } \\
\hline Exclusive breastfeeding & 54 & 28.0 \\
\hline Mixed feeding & 139 & 72.0 \\
\hline
\end{tabular}

frequency $(\mathrm{p}=0.02)$ and acceptable diets $(\mathrm{p}=0.03)$.

Logistic regression analysis (Table 5) revealed that there was a significant association between mother's knowledge about complementary feeding and minimum meal frequency $(\mathrm{OR}=2.21 ; 95 \% \mathrm{CI}: 1.31-3.73, \mathrm{p}=0.003)$. The odds that mothers who had good knowledge about complementary

Table 3. Complementary feeding practices of index infants in Osun State, Nigeria 2019 ( $\mathrm{N}=193)$

\begin{tabular}{l|r|r|}
\hline $\begin{array}{l}\text { Variables } \\
\text { Mother's knowledge about } \\
\text { complementary feeding }\end{array}$ & n & \\
\hline $\begin{array}{l}\text { Poor } \\
\text { Good }\end{array}$ & 55 & 28.5 \\
\hline $\begin{array}{l}\text { Commencement of complementary } \\
\text { feeding (months) }\end{array}$ & & \\
\hline$\leq 3$ & 77.5 \\
\hline $4-5$ & 62 & 39.9 \\
\hline 6 & 54 & 28.1 \\
\hline $\begin{array}{l}\text { Compliance with complementary } \\
\text { feeding indicators }\end{array}$ & & \\
\hline Meal frequency & & \\
\hline $\begin{array}{l}\text { Less than minimum meal frequency } \\
\text { *Minimum meal frequency }\end{array}$ & 123 & 63.7 \\
\hline $\begin{array}{l}\text { Dietary diversity } \\
\text { Less than minimum }\end{array}$ & 70 & 36.3 \\
\hline **Minimum & 92 & 47.7 \\
\hline $\begin{array}{l}\text { Acceptable diet } \\
\text { Less than minimum } \\
\text { ***Minimum }\end{array}$ & 101 & 52.3 \\
\hline
\end{tabular}

* An infant who was fed at least 2-3 times in the last 24 hours prior this survey was categorized to have received minimum meal frequency appropriate for age. ** An infant was categorized to have received minimum dietary diversity if fed with at least four out of the seven groups of foods recommended by WHO in the last 24 hours prior the survey. ${ }^{* * *}$ Infants who received both the minimum meal frequency and minimum dietary diversity the previous day prior the survey were considered to have met the WHO recommended minimum acceptable diet (WHO 2008).

Table 4. Bivariate analysis of mother's factors associated with complementary feeding of the index infant in Osun State, Nigeria 2019 ( $\mathrm{N}=193)$

\begin{tabular}{|c|c|c|c|c|c|c|}
\hline \multirow[t]{3}{*}{ Variables } & \multicolumn{6}{|c|}{ Complementary feeding indicators } \\
\hline & \multicolumn{2}{|c|}{ Meal frequency } & \multicolumn{2}{|c|}{ Dietary diversity } & \multicolumn{2}{|c|}{ Acceptable diet } \\
\hline & $\begin{array}{l}\text { Less than } \\
\text { minimum } \\
\text { n (\%) }\end{array}$ & $\begin{array}{c}\text { Minimum } \\
\text { n (\%) }\end{array}$ & $\begin{array}{c}\text { Less than } \\
\text { minimum } \\
\text { n (\%) }\end{array}$ & $\begin{array}{c}\text { Minimum } \\
\text { n (\%) }\end{array}$ & $\begin{array}{c}\text { Less than } \\
\text { minimum } \\
\text { n (\%) }\end{array}$ & $\begin{array}{c}\text { Minimum } \\
\text { n (\%) }\end{array}$ \\
\hline \multicolumn{7}{|c|}{ Knowledge } \\
\hline Poor & $42(76.4)$ & $13(23.6)$ & $34(61.8)$ & $21(38.2)$ & $48(87.3)$ & $7(12.7)$ \\
\hline Good & 81 (58.7) & 57 (41.3) & $58(42.0)$ & $80(58.0)$ & $96(69.6)$ & $42(30.4)$ \\
\hline$\chi^{2} \quad \mathrm{df} \quad \mathrm{p}$ & 5.31 & 0.02 & 6.17 & 0.01 & 6.51 & 0.01 \\
\hline
\end{tabular}


Table 4. Continued

\begin{tabular}{|c|c|c|c|c|c|c|c|c|c|}
\hline \multirow[t]{3}{*}{ Variables } & \multicolumn{9}{|c|}{ Complementary feeding indicators } \\
\hline & \multicolumn{3}{|c|}{ Meal frequency } & \multicolumn{3}{|c|}{ Dietary diversity } & \multicolumn{3}{|c|}{ Acceptable diet } \\
\hline & $\begin{array}{l}\text { Less than } \\
\text { minimum } \\
n(\%)\end{array}$ & & $\begin{array}{c}\text { Minimum } \\
\text { n (\%) }\end{array}$ & $\begin{array}{c}\text { Less than } \\
\text { minimum } \\
\text { n (\%) }\end{array}$ & & $\begin{array}{c}\text { Minimum } \\
\text { n (\%) }\end{array}$ & $\begin{array}{l}\text { Less than } \\
\text { minimum } \\
\text { n (\%) }\end{array}$ & & $\begin{array}{c}\text { Minimum } \\
\text { n (\%) }\end{array}$ \\
\hline \multicolumn{10}{|l|}{ Age (years) } \\
\hline $15-19$ & $9(90.0)$ & & $1(10.0)$ & $6(60.0)$ & & $4(40.0)$ & $10(100.0)$ & & $0(0.0)$ \\
\hline $20-24$ & $44(77.2)$ & & $13(22.8)$ & 33 (57.9) & & $24(42.1)$ & $51(89.5)$ & & $6(10.5)$ \\
\hline $25-29$ & $58(75.3)$ & & $19(24.7)$ & $54(70.1)$ & & 23 (29.9) & $68(88.3)$ & & $9(11.7)$ \\
\hline $30-34$ & 27 71.1) & & $11(28.9)$ & $21(55.3)$ & & $17(44.7)$ & $33(86.8)$ & & $5(13.2)$ \\
\hline $35-39$ & 8 (72.7) & & 3 (27.3) & $3(27.3)$ & & $8(72.7)$ & $10(90.9)$ & & $1(9.1)$ \\
\hline$\chi^{2}$ df $p$ & 1.57 & 4 & 0.81 & 8.68 & 4 & 0.07 & 0.28 & 4 & 0.99 \\
\hline \multicolumn{10}{|l|}{ Family type } \\
\hline Monogamous & $111(75.5)$ & & $36(24.5)$ & $84(57.1)$ & & $63(42.9)$ & 129 (87.8) & & $18(12.2)$ \\
\hline Polygamous & $25(75.8)$ & & $8(24.2)$ & 23 (69.7) & & $10(30.3)$ & $31(93.9)$ & & $2(6.1)$ \\
\hline Single parent & $10(76.9)$ & & $3(23.1)$ & $10(76.9)$ & & $3(23.1)$ & $12(92.3)$ & & $1(7.7)$ \\
\hline$\chi^{2}$ df $p$ & 0.01 & 2 & 0.99 & 3.33 & 2 & 0.19 & 1.21 & 2 & 0.55 \\
\hline \multicolumn{10}{|l|}{ Parity } \\
\hline Primipara & $35(85.4)$ & & $6(14.6)$ & $25(61.0)$ & & $16(39.0)$ & $41(100.0)$ & & $0(0.0)$ \\
\hline Multipara & $107(72.3)$ & & $41(27.7)$ & $91(61.5)$ & & $57(38.5)$ & 127 (85.8) & & $21(14.2)$ \\
\hline Grand multipara & $4(100.0)$ & & $0(0.0)$ & $1(25.0)$ & & $3(75.0)$ & $4(100.0)$ & & $0(0.0)$ \\
\hline$\chi^{2} \quad$ df $\quad p$ & 3.01 & 2 & 0.22 & 2.17 & 2 & 0.34 & 4.72 & 2 & 0.09 \\
\hline \multicolumn{10}{|l|}{ Place of residence } \\
\hline Rural & $75(77.3)$ & & $22(22.7)$ & $61(62.9)$ & & $36(37.1)$ & 87 (89.7) & & $10(10.3)$ \\
\hline Urban & $71(74.0)$ & & $25(26.0)$ & $56(58.3)$ & & $40(41.7)$ & $85(88.5)$ & & $11(11.5)$ \\
\hline$\chi^{2}$ df $\quad p$ & 0.30 & 1 & 0.59 & 0.42 & 1 & 0.52 & 0.07 & 1 & 0.80 \\
\hline \multicolumn{10}{|l|}{ Education level } \\
\hline No formal education & $7(58.3)$ & & $5(41.7)$ & $6(50.0)$ & & $6(50.0)$ & $9(75.0)$ & & $3(25.0)$ \\
\hline Primary education & $14(82.4)$ & & $3(17.6)$ & $11(64.7)$ & & $6(35.3)$ & $17(100.0)$ & & $0(0.0)$ \\
\hline Secondary education & $86(74.8)$ & & $29(25.2)$ & $73(63.5)$ & & $42(36.5)$ & 102 (88.7) & & $13(11.3)$ \\
\hline Tertiary education & $39(79.6)$ & & $10(20.4)$ & $27(55.1)$ & & $22(44.9)$ & $44(89.8)$ & & $5(10.2)$ \\
\hline$\chi^{2} \quad \mathrm{df} \quad \mathrm{p}$ & 2.83 & 3 & 0.42 & 1.70 & 3 & 0.64 & 2.89 & 3 & 0.41 \\
\hline \multicolumn{10}{|l|}{ Employment status } \\
\hline Not employed & $16(59.3)$ & & $11(40.7)$ & $17(63.0)$ & & $10(37.0)$ & $23(85.2)$ & & $4(14.8)$ \\
\hline Self employed & $97(78.9)$ & & $26(21.1)$ & $76(61.8)$ & & $47(38.2)$ & $115(93.5)$ & & $8(6.5)$ \\
\hline Government employed & $22(75.9)$ & & $7(24.1)$ & $18(62.1)$ & & $11(37.9)$ & $26(89.7)$ & & $3(10.3)$ \\
\hline Employed in private & $11(78.6)$ & & $3(21.4)$ & $6(42.9)$ & & $8(57.1)$ & $8(57.1)$ & & $6(42.9)$ \\
\hline$\chi^{2}$ df $p$ & 4.69 & 3 & 0.20 & 2.00 & 3 & 0.57 & 17.63 & 3 & 0.001 \\
\hline \multicolumn{10}{|c|}{ Average monthly income (NGN) } \\
\hline$<30000$ & $101(80.2)$ & & $25(19.8)$ & $81(64.3)$ & & $45(35.7)$ & $116(92.1)$ & & $10(7.9)$ \\
\hline$\geq 30000$ & $45(67.2)$ & & $22(32.8)$ & $36(53.7)$ & & $31(46.3)$ & $56(83.6)$ & & $11(16.4)$ \\
\hline$\chi^{2}$ df $p$ & 4.01 & 1 & 0.04 & 2.04 & 1 & 0.15 & 3.24 & 1 & 0.07 \\
\hline \multicolumn{10}{|l|}{ Socioeconomic status } \\
\hline Low & $30(75.0)$ & & $10(25.0)$ & $24(60.0)$ & & $16(40.0)$ & $35(87.5)$ & & $5(12.5)$ \\
\hline Middle & $91(76.5)$ & & $28(23.5)$ & $76(63.9)$ & & $43(36.1)$ & 107 (89.9) & & $12(10.1)$ \\
\hline High & 25 (71.4) & & $9(26.5)$ & $17(50.0)$ & & $17(50.0)$ & $30(88.2)$ & & $4(11.8)$ \\
\hline$\chi^{2}$ df $\quad p$ & 0.14 & 2 & 0.93 & 2.14 & 2 & 0.34 & 0.21 & 2 & 0.90 \\
\hline \multicolumn{10}{|c|}{ Household food security } \\
\hline High & $50(64.9)$ & & 27 (35.1) & $39(50.6)$ & & 38 (49.4) & $63(81.8)$ & & 14 (18.2) \\
\hline Low & $39(84.8)$ & & 7 (15.2) & $32(69.6)$ & & $14(30.4)$ & $44(95.7)$ & & $2(4.3)$ \\
\hline Very low & 57 (81.4) & & 13 (18.6) & 46 (65.7) & & $24(34.3)$ & $65(92.9)$ & & $5(7.1)$ \\
\hline$\chi^{2}$ df $p$ & 8.15 & 2 & 0.02 & 5.51 & 2 & 0.06 & 7.27 & 2 & 0.03 \\
\hline
\end{tabular}


feeding $(\mathrm{OR}=2.21)$ will feed their infants with recommended minimum meal frequency was twice higher than the odds for mothers who had poor knowledge. The regression analysis also showed that there was significant relationship between mother's education level and meal frequency (OR=0.18; 95\% CI: 0.05-0.59, p=0.01). Findings (Table 5) also showed significant relationship between household food security and meal frequency $(\mathrm{OR}=0.49 ; 95 \% \mathrm{CI}$ : $0.26-$ $0.94, \mathrm{p}=0.03$ ). Logistic regression analysis also revealed significant relationship between minimum dietary diversity and household food security (OR=0.47; 95\% CI: $0.26-0.83$, $\mathrm{p}=0.01$ ). Regression analysis further revealed significant association between minimum acceptable diet, mother's knowledge about complementary feeding (OR=2.67; 95\% CI: $1.38-5.14, \mathrm{p}=0.003$ ) and mother's education level (OR=0.11; 95\% CI: 0.02-0.71, $\mathrm{p}=0.02$ ) (Table 5). The odds $(\mathrm{OR}=2.67)$ that mothers who had good knowledge about complementary feeding will feed their infants with minimum

Table 5. Logistic regression analysis of mother's factors associated with minimum meal frequency, minimum dietary diversity and minimum acceptable $\operatorname{diet}(\mathrm{N}=193)$

\begin{tabular}{|c|c|c|c|c|c|c|c|c|c|}
\hline \multirow[t]{2}{*}{ Variables } & \multicolumn{3}{|c|}{ Minimum meal frequency } & \multicolumn{3}{|c|}{$\begin{array}{c}\text { Minimum dietary } \\
\text { diversity }\end{array}$} & \multicolumn{3}{|c|}{ Minimum acceptable diet } \\
\hline & p & OR & $95 \% \mathrm{CI}$ & $\mathbf{p}$ & OR & CI & $\mathbf{p}$ & OR & CI \\
\hline \multicolumn{10}{|l|}{ Knowledge } \\
\hline Poor & & 1 & & & 1 & & & 1 & \\
\hline Good & 0.003 & 2.21 & $1.31-3.73$ & 0.05 & 1.58 & $0.99-2.50$ & 0.003 & 2.67 & $1.38-5.14$ \\
\hline \multicolumn{10}{|l|}{ Age (years) } \\
\hline$<20$ & & 1 & & & 1 & & & 1 & \\
\hline $20-29$ & 0.22 & 2.24 & $0.62-8.04$ & 0.46 & 0.67 & $0.23-1.95$ & 0.28 & 2.48 & $0.47-13.01$ \\
\hline $30-39$ & 0.14 & 2.87 & $0.71-11.63$ & 0.83 & 1.14 & $0.35-3.74$ & 0.36 & 2.33 & $0.39-13.99$ \\
\hline \multicolumn{10}{|l|}{ Family type } \\
\hline Monogamous & & 1 & & & 1 & & & 1 & \\
\hline Polygamous & 0.70 & 0.88 & $0.45-1.71$ & 0.36 & 0.76 & $0.42-1.37$ & 0.21 & 0.57 & $0.24-1.37$ \\
\hline Single parent & 0.39 & 1.58 & $0.56-4.47$ & 0.19 & 0.52 & $0.20-1.38$ & 0.35 & 1.82 & $0.52-6.37$ \\
\hline \multicolumn{10}{|l|}{ Parity } \\
\hline Primipara & & 1 & & & 1 & & & 1 & \\
\hline Multipara & 0.32 & 1.37 & $0.73-2.58$ & 0.51 & 0.83 & $0.48-1.44$ & 0.09 & 2.03 & $0.90-4.58$ \\
\hline Grand multipara & 0.36 & 0.35 & $0.04-3.20$ & 0.42 & 2.06 & $0.36-11.75$ & 0.91 & 1.14 & $0.12-11.29$ \\
\hline \multicolumn{10}{|l|}{ Place of residence } \\
\hline Rural & & 1 & & & 1 & & & 1 & \\
\hline Urban & 0.20 & 0.64 & $0.32-1.27$ & 0.88 & 1.05 & $0.57-1.92$ & 0.80 & 0.44 & $0.17-1.11$ \\
\hline \multicolumn{10}{|l|}{ Education level } \\
\hline No formal education & & 1 & & & 1 & & & 1 & \\
\hline Primary & 0.07 & 0.30 & $0.08-1.09$ & 0.34 & 0.56 & $0.17-1.82$ & 0.02 & 0.11 & $0.02-0.71$ \\
\hline Secondary & 0.14 & 0.45 & $0.16-1.29$ & 0.10 & 0.43 & $0.16-1.17$ & 0.23 & 0.49 & $0.15-1.59$ \\
\hline Tertiary & 0.01 & 0.18 & $0.05-0.59$ & 0.07 & 0.36 & $0.12-1.10$ & 0.05 & 0.26 & $0.07-0.98$ \\
\hline \multicolumn{10}{|l|}{ Employment status } \\
\hline Employed & & 1 & & & 1 & & & 1 & \\
\hline Unemployed & 0.28 & 1.58 & $0.69-3.63$ & 0.76 & 0.89 & $0.42-1.90$ & 0.64 & 1.27 & $0.47-3.42$ \\
\hline \multicolumn{10}{|c|}{ Average monthly income (NGN) } \\
\hline$<30000$ & & 1 & & & 1 & & & 1 & \\
\hline$\geq 30000$ & 0.15 & 1.54 & $0.85-2.77$ & 0.84 & 1.06 & $0.62-1.82$ & 0.54 & 1.24 & $0.62-2.49$ \\
\hline \multicolumn{10}{|c|}{ Household food security } \\
\hline High & & 1 & & & 1 & & & 1 & \\
\hline Low & 0.03 & 0.49 & $0.26-0.94$ & 0.01 & 0.47 & $0.26-0.83$ & 0.05 & 0.46 & $0.21-1.02$ \\
\hline Very low & 0.06 & 0.57 & $0.32-1.03$ & 0.05 & 0.59 & $0.35-1.00$ & 0.44 & 0.76 & $0.39-1.51$ \\
\hline Constant & 0.24 & 0.35 & & 0.10 & 3.68 & & 0.04 & 0.10 & \\
\hline
\end{tabular}

OR: odds ratio. 
acceptable diets was higher than the odds for mothers who had poor knowledge about complementary feeding.

\section{DISCUSSION}

This study observed that majority of mothers had good knowledge about complementary feeding. Nutritional knowledge of mothers and those in primary care is important towards reduction in childhood malnutrition. This assertion corroborates the submission of a study in Northwestern Nigeria, which observed that the quality and quantity of feeding in early childhood depend largely on the basic nutritional knowledge of their mothers ${ }^{18}$. The above submissions underscore the importance of mother's knowledge for ensuring optimal infant feeding practices.

This study also observed that $28.0 \%$ of mothers exclusively breastfed their infants in the first six months. This observation is comparable with a finding from a study conducted in Lagos, Nigeria, which reported that the proportion of exclusive breastfeeding among women in urban communities of Lagos State was $29 \%{ }^{27}$. This observation also corroborates a study conducted in Addis Ababa, Ethiopia, which found that the proportion of exclusively breastfed infants in Sub-Saharan Africa was 35\% ${ }^{28}$. The Nigeria Demographic and Health Survey reported that 29\% of children aged $<6$ months are exclusively breastfed in Nigeria ${ }^{6}$.

In addition, this study found that $39.9 \%$ of mothers introduced complementary feeding within the first 3 months while $32.1 \%$ commenced complementary feeding between the 4th and 5th month. Similar studies on complementary feeding conducted in Iraq and the United Arab Emirates observed that $78.6 \%$ of infants in Iraq and $70 \%$ of infants in the United Arab Emirates commenced complementary foods between the 4 th and 6 th month ${ }^{29}$. A multicenter study conducted in Italy, Belgium, Germany, Spain and Poland reported that $25 \%$ of the infants studied commenced complementary feeding before the 4 th month while approximated $90 \%$ of the infants commenced solid foods by the 6 th month ${ }^{30}$. The above observations are comparable with the finding from a study conducted in Northwestern Nigeria which reported that $17.8 \%$ of the infants studied commenced complementary food between the 1st and 2nd month while $41.2 \%$ of infants commenced complementary foods from the 3 rd month ${ }^{12}$. A similar finding was reported in Cross River State, Nigeria, where it was found that $85.4 \%$ of children aged $<5$ years had early introduction of complementary foods ${ }^{13}$. Early introduction of complementary foods (before the 6th month) has been found to be associated with varying degree of health risks and childhood illnesses including food-borne infectious diseases ${ }^{14}$. Inappropriate timing of initiation of complementary feeding is associated with several nutritionrelated morbidities and mortalities among children aged $<5$ years in developing countries of the world.

Furthermore, findings from this study showed that 36.3\% of the mothers fed their infants with minimum meal frequency, $52.3 \%$ fed their infants with the minimum dietary diversity while $25.4 \%$ of the mothers fed their infants with minimum acceptable diets. These findings are comparable with the observation from the study conducted in Delta State, Nigeria, which found that $54.0 \%$ of mothers studied fed their infants three times daily in addition to breastfeeding ${ }^{14}$. The Nigeria Demographic and Health Survey, however, reported that only $11 \%$ of children aged 6-23 months are fed in accordance with the criteria for a minimum acceptable $\operatorname{diet}^{6}$. In a study to examine the proportion of infants who received minimum dietary diversity and minimum meal frequency among infants and young children aged 6-23 months in Ethiopia, it was observed that the proportion of children who were fed with minimum recommended dietary diversity was $10.8 \%$ while about $50 \%$ of these children received the recommended meal frequency of complementary foods for age ${ }^{31}$. This finding corroborates the report of a study conducted to evaluate dietary diversity of complementary foods in Mongolia which revealed that majority of children studied consumed less than two food groups out of the recommended seven groups, which was below the recommended minimum dietary diversity of at least four foods groups ${ }^{32}$. In addition to the above findings, a cross-sectional study conducted in Osun State, Nigeria, revealed that mostly consumed diets among children aged 1-2 years were cereals and tuber food with minimal consumption of animal protein, fruits and vegetables ${ }^{29}$. The study further recommended adequate dietary diversity for infants and young children. In their study on nutritional status of infants in Akpabuyo, Cross River State, Nigeria, Udoh and Amadu ${ }^{13}$ reported that $36.7 \%$ of the infants received minimum meal frequency, $31.5 \%$ received minimum dietary diversity while $7.3 \%$ received minimum acceptable diet.

Analysis of factors associated with complementary feeding at the bivariate level revealed that meal frequency was significantly associated with mother's knowledge about complementary feeding, mother's monthly income and household food security status. Mother's knowledge about complementary feeding was also significantly associated with meal diversity while minimum acceptable diet was significantly associated with mother's employment status and household food security.

Regression analysis of factors associated with complementary feeding, however, revealed that minimum meal frequency remained significantly associated with mother's knowledge about complementary feeding, educational level and household food security. Regression analysis also revealed that minimum dietary diversity was significantly associated with household food security while minimum acceptable diet was significantly associated with mother's knowledge about complementary feeding and educational level. The above findings are comparable with the report of a study in South-West Nigeria on attitude, knowledge and practice of infant feeding which observed an association between mother's knowledge about infant feeding and infant's feeding practices ${ }^{27}$. In addition, studies conducted in South-West Nigeria on determinants of 
children aged $<5$ years feeding practices in also identified place of residence as a factor that influenced childhood feeding practices ${ }^{26,33}$. A cross-sectional study by Ogunba ${ }^{25}$ among children aged 0-2 years in Osun State, South-West Nigeria, also observed significant relationship between household socioeconomic status and dietary diversity. A similar finding was observed in another Nigerian study on sociocultural factors affecting Nigerian mother's weaning practices conducted in Zaria, Northern Nigeria, which observed significant association between sociocultural factors and mother's weaning practices ${ }^{17}$. The above observations are consistent with findings from a study conducted in Nepal which observed an association between infants' feeding practices and maternal characteristics such as education level, occupational status, place of residence, knowledge about infants' diet, and monthly income ${ }^{26}$. Furthermore, a study conducted in Kenya on sociocultural practices and beliefs influencing infant and young child feeding concluded that cultural beliefs, taboos and certain food restrictions strongly influence breastfeeding and complementary feeding practices ${ }^{17}$. An effective nutrition intervention for mothers on infants feeding practices should incorporate strategies aimed at reducing myths and misconceptions related to infants feeding in this study area.

\section{Strengths and limitations}

This study involved postpartum mothers in Osun State, South-West Nigeria. Findings from this study may therefore not be considered nationally representative. However, findings from this study are comparable with data obtained from different regions across the country. Findings are also comparable with data obtained from the national survey such as the Nigeria Demographic and Health Survey (2018) as well as data from different African sub-regions.

\section{CONCLUSIONS}

Mothers' nutritional knowledge, education and household food security were the main predictors of complementary feeding practices among studied mothers; effective nutritional intervention on infants and childhood feeding should take cognizance of these variables.

Advocacy must focus on interventions that could improve household food security and mothers' socioeconomic empowerment in order to achieve a significant reduction in childhood malnutrition and related burdens.

\section{REFERENCES}

1. Demilew YM, Tafere TE, Abitew DB. Infant and young child feeding practice among mothers with 0-24 months old children in Slum areas of Bahir Dar City, Ethiopia. Int Breastfeed J. 2017;12:26. doi:10.1186/s13006-017-0117-x

2. World Health Organization. Malnutrition. Updated June 9, 2021. Accessed October 14, 2020. https://www.who.int/ news-room/fact-sheets/detail/malnutrition

3. World Health Organization. Infant and young child feeding.
Updated June 9, 2021. Accessed September 17, 2019. https://www.who.int/news-room/fact-sheets/detail/infantand-young-child-feeding

4. Roche ML, Creed-Kanashiro HM, Tuesta I, Kuhnlein HV. Infant and young child feeding in the Peruvian Amazon: the need to promote exclusive breastfeeding and nutrientdense traditional complementary foods. Matern Child Nutr. 2011;7(3):284-294. doi:10.1111/j.1740-8709.2009.00234.x

5. UNICEF, World Health Organization, World Bank Group. Levels and trends in child malnutrition: Joint child malnutrition estimates. Key findings of the 2017 edition. United Nations Children's Fund, World Health Organization, World Bank Group; 2017. Accessed June 10, 2019. https://apps.who.int/ nutgrowthdb/jme_brochoure2017.pdf?ua=1\&ua=1

6. National Population Commission, ICF. Nigeria Demographic and Health Survey 2018. National Population Commission, ICF; 2019. Accessed September 23, 2019. https://www. dhsprogram.com/pubs/pdf/FR359/FR359.pdf

7. National Bureau of Statistic. National Nutrition and Health Survey (NNHS) 2018: Report on the Nutrition and Health Situation of Nigeria. National Bureau of Statistic; 2018. Accessed June 8, 2021. https://www.unicef.org/nigeria/ media/2181/file/Nigeria-NNHS-2018.pdf

8. World Health Organization. e-Library of Evidence for Nutrition Actions (eLENA): Exclusive breastfeeding for optimal growth, development and health of infants. 2019. Accessed September 10, 2019. https://www.who.int/elena/ titles/exclusive_breastfeeding/en/

9. White JM, Bégin F, Kumapley R, Murray C, Krasevec J. Complementary feeding practices: Current global and regional estimates. Matern Child Nutr. 2017;13(S2) (suppl):e12505. doi:10.1111/mcn.12505

10. Olatona FA, Odozi MA, Amu EO. Complementary Feeding Practices among Mothers of Children under Five Years of Age in Satellite Town, Lagos, Nigeria. Food Public Health. 2014;4(3):93-98. doi:10.5923/j.fph.20140403.04

11. World Health Organization. Indicators for assessing infant and young child feeding practices: Part 1: Definitions. Conclusions of a consensus meeting, November 6-8, 2007; Washington, DC. Accessed August 5, 2020. https://apps.who.int/iris/ bitstream/handle/10665/43895/9789241596664_eng. pdf;jsessionid=6C4FE78D2B4502932546

12. Anigo K, Ameh D, Ibrahim S, Danbauchi S. Nutrient composition of complementary food gruels formulated from malted cereals, soybeans and groundnut for use in North-western Nigeria. African journal of food science. 2010;4(3):65-72. doi:10.5897/AJFS.9000200

13. Udoh EE, Amodu OK. Complementary feeding practices among mothers and nutritional status of infants in Akpabuyo Area, Cross River State Nigeria. Springerplus. 2016;5(1):2073. doi:10.1186/s40064-016-3751-7

14. Tang L, Lee AH, Binns CW. Predictors of early introduction of complementary feeding: longitudinal study. Pediatr Int. 2015;57(1):126-130. doi:10.1111/ped.12421

15. Ogbe FA, Page A, Idoko J, Claudio F, Agho KE. Trends in 
complementary feeding indicators in Nigeria, 2003-2013. BMJ. 2015;5(10):e008467. doi:10.1136/bmjopen-2015-008467

16. National Population Commission, ICF International. Nigeria Demographic and Health Survey 2013. National Population Commission, ICF International; 2014. Accessed August 26, 2018. https://dhsprogram.com/pubs/pdf/FR293/FR293.pdf

17. Karigi LN, Mutuli LA, Bukhala P. Socio-cultural practices and beliefs influencing infant and young child feeding in Lubao sub-location Kakamega county. Journal of Nutritional Health \& Food Engineering. 2016;5(1):568-571. doi:10.15406/jnhfe.2016.05.00160

18. Sufiyan MB, Bashir SS, Umar AA. Effect of maternal literacy on nutritional status of children under 5 years of age in the Babban-Dodo community Zaria city, Northwest Nigeria. Annals of Nigerian medicine. 2012;6(2):61-64. doi:10.4103/0331-3131.108110

19. National Bureau of Statistics E-Library. National Bureau of Statistics. Accessed May 12, 2019. https://nigerianstat.gov. ng/elibrary

20. Ajala OA, Sanni L, Adeyinka SA. Accessibility to Health Care Facilities: A Panacea for Sustainable Rural Development in Osun State Southwestern, Nigeria. J Hum Ecol. 2005;18(2):121-128. doi:10.1080/09709274.2005.11905819

21. Fautsch Macías M, Glasauer P. Guidelines for assessing nutrition-related assessing nutrition-related knowledge, attitudes and practices. Food and Agriculture Organization of the United Nations; 2014. Accessed October 23, 2019. http://www.fao.org/3/i3545e/i3545e.pdf

22. U.S. Household Food Security Survey Module: Six-Item Short Form Economic Research Service, USDA, September 2012. U.S. Department of Agriculture, Economic Research Service; 2012. Updated September 9, 2020. Accessed December 12, 2019. https://www.ers.usda.gov/media/8282/short2012.pdf

23. Food and Agriculture Organization of the United Nations. Dietary assessment: a resource guide to method selection and application in low resource settings. Food and Agriculture Organization of the United Nations; 2018. Accessed January 10, 2020. http://www.fao.org/3/i9940en/I9940EN.pdf

24. Wani RT. Socioeconomic status scales-modified Kuppuswamy and Udai Pareekh's scale updated for 2019. J Family Med Prim Care. 2019;8(6):1846-1849. doi:10.4103/jfmpc.jfmpc_288_19 25. Ogunba BO. Diet Diversity in Complementary Feeding and Nutritional Status of Children Aged 0 to 24 Months

\section{ACKNOWLEDGEMENTS}

Authors wish to acknowledge the chairpersons of Ife Central, Ife East, Oriade and Atakunmosa West Local Government Areas where this study was conducted.

\section{CONFLICTS OF INTEREST}

The authors have completed and submitted the ICMJE Form for Disclosure of Potential Conflicts of Interest and none was reported.

FUNDING

Authors of this manuscript did not receive funding or any form of financial assistance from any government or organization during conduct and publishing of this study. in Osun State, Nigeria: A Comparison of the Urban and Rural Communities. Infant, child \& adolescent nutrition. 2010;2(6):330-335. doi:10.1177/1941406410385451

26. Joshi HS, Gupta R, Joshi MC, Mahajan V. Determinants of Nutritional Status of School Children-A Cross Sectional Study in the Western Region of Nepal. Natl J Integr Res Med. 2011;2(1):10-15. Accessed September 12, 2019. http:// nicpd.ac.in/ojs-/index.php/njirm/article/view/1889/1710

27. Balogun MR, Okpalugo OA, Ogunyemi AO, Sekoni AO. Knowledge, Attitude, and Practice of Breastfeeding: A Comparative Study of Mothers in Urban and Rural Communities of Lagos, Southwest Nigeria. Niger Med J. 2017;58(4):123-130. doi:10.4103/nmj.NMJ_289_16

28. Elyas L, Mekasha A, Admasie A, Assefa E. Exclusive Breastfeeding Practice and Associated Factors among Mothers Attending Private Pediatric and Child Clinics, Addis Ababa, Ethiopia: A Cross-Sectional Study. Int J Pediatr. 2017;2017:8546192. doi:10.1155/2017/8546192

29. Caroli M, Mele RM, Tomaselli MA, Cammisa M, Longo F, Attolini E. Complementary feeding patterns in Europe with a special focus on Italy. Nutr Metab Cardiovasc Dis. 2012;22(10):813-818. doi:10.1016/j.numecd.2012.07.007

30. Alvisi P, Brusa S, Alboresi S, et al. Recommendations on complementary feeding for healthy, full-term infants. Ital J Pediatr. 2015;41:36. doi:10.1186/s13052-015-0143-5

31. Oyibo PG, Okperi BO, Oyibo IA. Breastfeeding pattern among mothers nursing infants aged 3-6 months in Abraka, Delta State, Nigeria. Continental Journal of Medical Research. 2011;5(2):19-23. Accessed Feruary 16, 2019. https://www. academia.edu/1398604/BREASTFEEDING_PATTERN_ AMONG_MOTHERS_NURSING_INFANTS_AGED_3_6_ MONTHS_IN_ABRAKA_DELTA_STATE_NIGERIA

32. Aemro M, Mesele M, Birhanu Z, Atenafu A. Dietary Diversity and Meal Frequency Practices among Infant and Young Children Aged 6-23 Months in Ethiopia: A Secondary Analysis of Ethiopian Demographic and Health Survey 2011. J Nutr Metab. 2013;2013:782931. doi:10.1155/2013/782931

33. Adeomi AA, Adeoye 0, Bamidele JO, Abodunrin OL, Odu OO, Adeomi OA. Pattern and determinants of the weight status of school-age children from rural and urban communities of Osun state, Nigeria: A comparative study. Journal of medical nutrition \& nutraceuticals. 2015;4(2):107-114. doi:10.4103/2278-019X.151800

\section{ETHICAL APPROVAL AND INFORMED CONSENT}

Ethical approval was obtained from Ethics and Research Committee of the Institute of Public Health, Obafemi Awolowo University, Ile-Ife, Osun state (Health Research Ethics Committee No. IPH/OAU/12/1138). Permission to collect data was obtained from the authorities of Ife Central, Ife East, Atakunmosa West and Oriade Local Government Areas of Osun State. Informed consent was obtained from mothers prior to data collection, who were also informed that they are free to withdraw from the study anytime.

\section{PROVENANCE AND PEER REVIEW}

Not commissioned; externally peer reviewed. 